\title{
Empirical Studies of Collaborative Information Seeking: A Review of Methodological
} Issues

Hertzum, Morten; Hansen, Preben

Published in:

Journal of Documentation

DOI:

10.1108/JD-05-2018-0072

Publication date:

2019

Document version

Peer reviewed version

Citation for published version (APA):

Hertzum, M., \& Hansen, P. (2019). Empirical Studies of Collaborative Information Seeking: A Review of Methodological Issues. Journal of Documentation, 75(1), 140-163. https://doi.org/10.1108/JD-05-2018-0072 


\title{
Empirical Studies of Collaborative Information Seeking: A Review of Methodological Issues
}

\author{
Morten Hertzum, University of Copenhagen, hertzum@hum.ku.dk \\ Preben Hansen, Stockholm University, preben@dsv.su.se
}

\begin{abstract}
Purpose - Information seeking is often performed in collaborative contexts. The research into such collaborative information seeking (CIS) has been proceeding since the 1990s but lacks methodological discussions. This paper analyzes and discusses methodological issues in existing ClS studies.

Design/methodology/approach - We systematically review 69 empirical CIS studies.

Findings - The review shows that the most common methods of data collection are lab experiments (43\%), observation (19\%), and surveys (16\%), that the most common methods of data analysis are description (33\%), statistical testing (29\%), and content analysis (19\%), and that CIS studies involve a fairly even mix of novice, intermediate, and specialist participants. However, we also find that CIS research is dominated by exploratory studies, leaves it largely unexplored in what ways the findings of a study may be specific to the particular study setting, appears to assign primacy to precision at the expense of generalizability, struggles with investigating how CIS activities extend over time, and provides data about behavior to a larger extent than about reasons, experiences, and especially outcomes.

Research limitations/implications - The major implication of this review is its identification of the need for a shared model to which individual CIS studies can contribute in a cumulative manner. To support the development of such a model we discuss a model of the core CIS process and a model of the factors that trigger CIS.

Originality/value - This study assesses the current state of $\mathrm{CIS}$ research, provides guidance for future CIS studies, and aims to inspire further methodological discussion.
\end{abstract}

Keywords: collaborative information seeking, collaborative search, information behavior, research methods

Paper type: literature review

\section{Introduction}

Information seeking is integral to many collaborative activities. Teams of professionals seek and interact with information in engineering (Poltrock et al., 2003), government (Hansen and Järvelin, 2005), healthcare (Reddy and Jansen, 2008), research (Farooq et al., 2009), and various other work contexts. Similarly, people may seek information collaboratively in leisure situations (Amershi and Morris, 2008), when they attend school (Knight and Mercer, 2015), and so forth. The research area of collaborative 
information seeking (CIS) has emerged around these activities and established a research base that evolves around empirical studies. Yet, CIS research lacks methodological discussions, partly because the foci of different CIS studies have called for the use of a variety of methods. This study reviews methodological issues in empirical CIS studies to assess the current state of CIS research, provide guidance for future $\mathrm{CIS}$ studies, and inspire further methodological discussion.

CIS phenomena present many open questions. For example, some CIS studies aim to unravel what activities people engage in to seek information collaboratively and competently in real-life situations, while other studies aim to create and evaluate technologies to support people in their collaborative search for information. As a consequence, CIS research involves and embeds research from several other research areas, such as computer-supported cooperative work, human-computer interaction, information seeking, (interactive) information retrieval, library and information science, and social media. In this study we take CIS to imply a focus on the psychological, social, and possibly organizational aspects of how people seek information collaboratively. This way we, for example, exclude studies that are purely about the algorithmic aspects of $\mathrm{CIS}$ technologies, purely about individual information seeking, and purely about information sharing. But the studies included in our review may of course contain elements of, say, information sharing as part of their treatment of CIS phenomena.

This review concerns the methods used in CIS studies. Methodological issues are important because they frame what studies are about and what can, and cannot, be concluded from them. To the best of our knowledge the only previous discussion of methods in CIS studies is Hyldegård et al. (2015). However, they merely discussed the methods of three CIS studies. In this paper we analyze and discuss methodological issues in $69 \mathrm{CIS}$ studies following a systematic review approach. We review these CIS studies with respect to their level of investigation, methods of data collection, groups of participants, types of data collected, and methods of data analysis. Figure 1 illustrates the ten classifications that enter into our coding scheme and form the basis of our analysis and discussion. With the increasing number of $\mathrm{CIS}$ studies it has become pertinent to transition from exploratory toward more focused studies to advance CIS research. Such a transition is to a large extent methodological. We hope this review will support the CIS community in making this transition.

In the following we first define the CIS concept to provide a background for the review. Then we describe our systematic review method, including its inclusion and exclusion criteria, and present the review results. Finally, we discuss patterns in the results and implications for future CIS studies. 


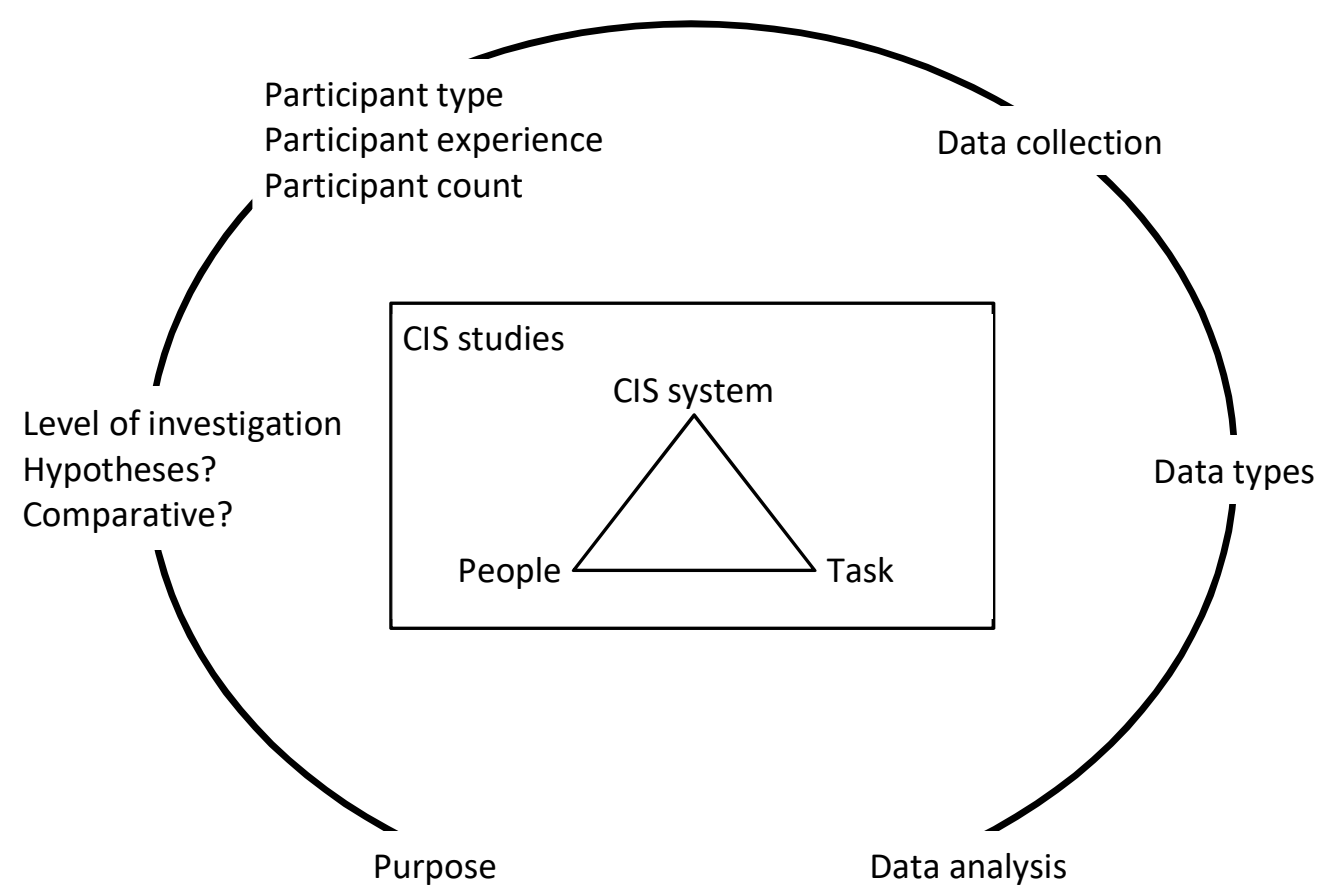

Figure 1. CIS studies encircled by the ten classifications employed in this review.

\section{Background}

Research on the collaborative aspects of information seeking is relatively young. Many of the influential models of information seeking still portray it as an activity performed by individual information seekers (e.g., Case and Given, 2016; Kuhlthau, 2004; Wilson, 1999). CIS research focuses on how groups of people perform activities such as realizing their information needs, preparing for the search activity, collecting information, making sense of it, sharing resulting insights, and using the information in their work and leisure activities. A better understanding of CIS phenomena will provide improved possibilities and motivation for developing systems and services that support information behavior and task accomplishment in social, practical, and professional contexts.

An early definition of CIS takes it to be "any activity that collectively resolves an information problem taken by members of a work-team, regardless of the nature of the actual retrieval of information" (Fidel et al., 2000, p. 236). This definition is explicitly inclusive and appears geared toward the exploratory nature of an early study. Later definitions have varied with the focus of the studies. An influential difference is whether studies primarily focus on the involved people's interactions with a CIS system or with a work task (see the center box of Figure 1). For example, Paul and Morris (2009) emphasize system interactions and focus on CIS in relation to a single technology, the Web. They define collaborative search descriptively as the "many scenarios where groups collaboratively search the Web to find information" (p. 1771). In contrast, Hansen and Järvelin (2005) emphasize professional work situations and define CIS in relation to the tasks the information is intended to support. According to their definition CIS is "related to a specific problem solving activity that, implicitly or explicitly, involves human beings interacting with other human(s) directly and/or through texts" (Hansen and Järvelin, 2005, p. 1102).

In his review of CIS research Foster (2006, p. 330) combines system-oriented and work-oriented perspectives by defining CIS as "the study of systems and practices that enable individuals to collaborate 
during the seeking, searching and retrieval of information". We adopt this definition of CIS in the present review. An implicit feature of this definition is that it is open to elements performed by individual actors as long as these elements serve to enable collaboration about the acquisition of information. This feature has subsequently been accentuated by Hertzum (2008), who characterizes CIS as the combination of information-seeking activities, which can be performed by individual actors or by several actors in collaboration, and collaborative-grounding activities, which are necessarily collaborative. Shah (2014, p. 216) makes a similar point when he distinguishes two ways in which collaboration and information seeking are connected in CIS studies: In "collaboration to help information seeking" the actors perform information-seeking activities together. In "information seeking to help collaboration" the actors, mainly, collaborate in the activities that lead up to and follow after the information seeking as such.

\section{Review method}

The present study followed a systematic review process, see Figure 2 . We chose a systematic review to be explicit about how the reviewed studies were identified and analyzed. In the following, we describe the five stages of the process, which resulted in the inclusion of $69 \mathrm{CIS}$ papers in the review.

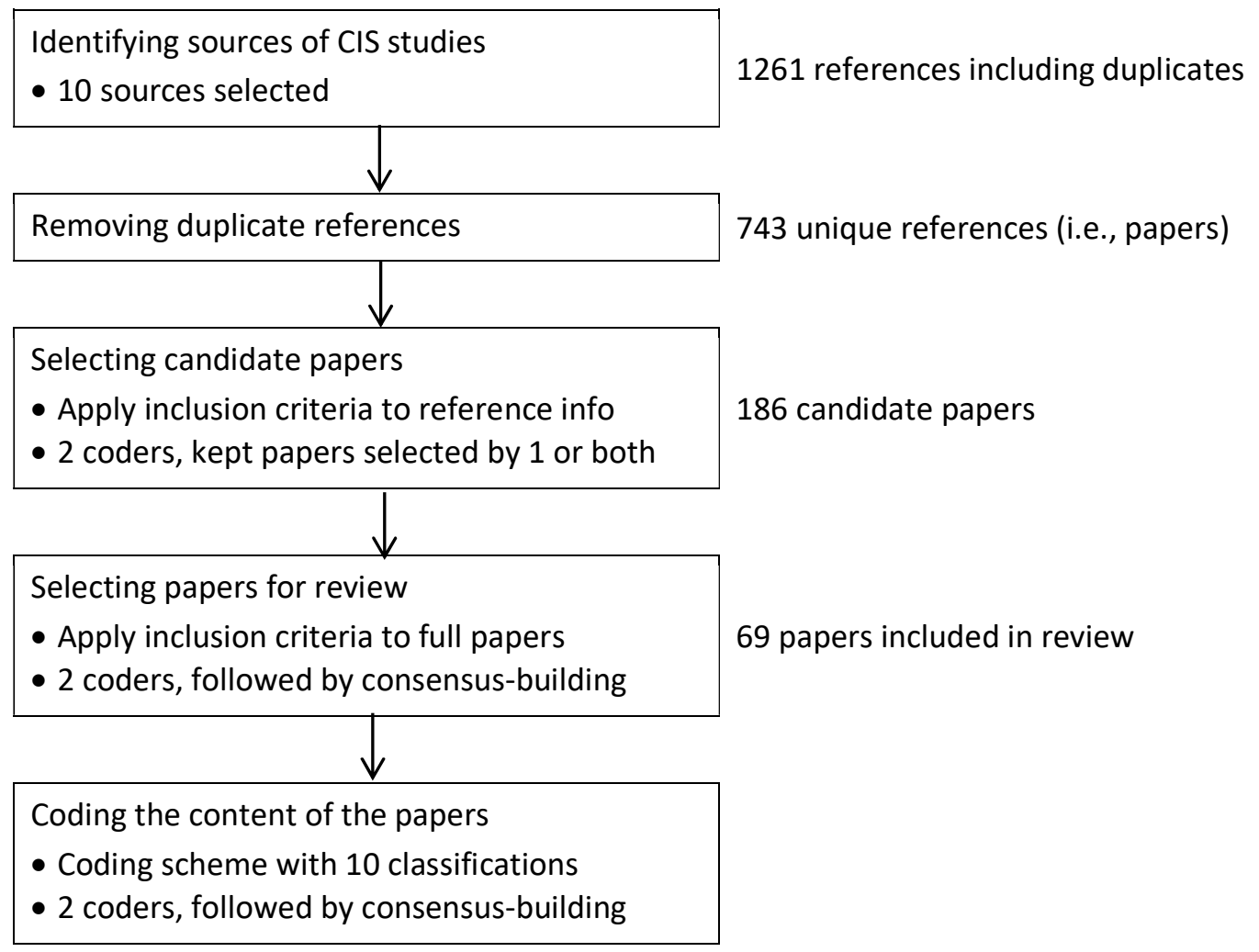

Figure 2. The process of selecting and coding the collaborative information seeking (CIS) studies 


\subsection{Identifying sources of CIS studies}

The first stage was to identify the sources from which CIS papers would be selected for our review. CIS papers are scattered across many journals and conferences because this research area does not have its own journal, conference series, or book series. The scatteredness prevented us from selecting specified journals and conferences as our sources of CIS papers. We also chose against finding CIS papers by searching for papers containing specified terms because it was unclear to us which terms to include in the query to capture the papers that did not make use of the label "collaborative information seeking". Instead we utilized the presence of a number of recent books, edited collections, reviews, and introductory articles in the area of collaborative information seeking/collaborative information retrieval/collaborative search. By focusing on these milestone sources as well as on obtaining a spread of early and new sources, we identified ten sources of CIS papers, see Table 1 . The ten sources were published between 2006 and 2016, had passed the quality assessment of peer-reviewing, and contained a total of 1261 references.

Table 1. Sources of studies about collaborative information seeking

\begin{tabular}{llc}
\hline Source & Type & References \\
\hline Foster (2006) & Review & 76 \\
Golovchinsky et al. (2009) & Introductory article & 8 \\
Hansen et al. (2015) & Edited collection & 513 \\
Hertzum (2008) & Introductory article & 33 \\
Morris and Teevan (2010) & Book & 86 \\
Shah (2010) & Review & 92 \\
Shah (2012) & Book & 247 \\
Shah (2014) & Review & 99 \\
Shah et al. (2014) & Edited collection & 87 \\
Tamine and Soulier (2016) & Introductory article & 20 \\
\hline
\end{tabular}

\subsection{Removing duplicate references}

The ten sources referenced some of the same publications. Thus, the total set of 1261 references contained a number of duplicates. In the second stage the duplicates were identified and removed through a process of automated pattern matching and manual follow-up. After duplicate removal we had 743 unique references.

\subsection{Selecting candidate papers}

While the previous stages aimed to ensure that the 743 unique references included an extensive sample of disparate CIS studies, there were also non-CIS studies among the references. At the third stage we reduced the 743 unique references to a set of candidate papers that were most likely about CIS. We postponed the final selection of which papers to review until the fourth stage. The rationale for confining the third stage to tentative selection was to be able to remove the majority of the non-CIS studies in a cost-efficient manner: We selected the candidate papers on the basis of the reference as it appeared in the source. To determine whether to include a paper among the candidate papers we matched its 
reference against a list of inclusion criteria. The inclusion criteria were specified prior to the matching process; a candidate paper had to satisfy all eight of them. We included:

- Studies of collaboration to help information seeking as well as studies of information seeking to help collaboration (conversely, we excluded studies of individual information seeking).

- Studies of the psychological, social, and organizational aspects of how people seek information (conversely, we excluded studies of the algorithmic aspects of providing technological support for information retrieval).

- Studies in which the actors who collaborated on a task needed to consult resources external to their own knowledge (conversely, we excluded studies restricted to information sharing within the group of collaborating actors).

- Studies of information needs, seeking, and use (conversely, we excluded studies of knowledge management, which tends to focus on the organization rather than the information seekers).

- Empirical studies (conversely, we excluded papers not based on empirical data and empirical papers that did not contain a description of their method).

- Research papers published in journals, edited books, and conference proceedings (conversely, we excluded books, theses, and publications such as posters and workshop contributions).

- Only the most extensive paper when multiple versions existed (e.g., a study published first at a conference and then in a journal).

- Papers in English.

The two authors independently matched the 743 references against the inclusion criteria and assessed which papers to include among the candidate papers. As a precursor to this assessment the authors initially assessed 60 references and discussed their assessments of whether they were candidate papers. This discussion served to reach consensus about the inclusion or exclusion of the 60 references and to create a shared understanding of the inclusion criteria. On this basis both authors assessed the remaining 683 references. Cohen's (1960) kappa of the agreement between the authors was .63, which indicated "substantial" agreement (Landis and Koch, 1977). We defined the set of candidate papers as the 186 papers selected for inclusion by one or both authors.

\subsection{Selecting papers for review}

The fourth stage consisted of assessing the 186 tentatively selected papers to make the final selection of which papers to include in the review. This final selection was made on the basis of the full text of the 186 candidate papers. The authors independently matched these papers against the inclusion criteria, which were the same as in the previous stage. The agreement (Cohen's kappa) between the authors was .64, again indicating "substantial" agreement (Landis and Koch, 1977). For 153 papers the authors agreed; the 33 disagreements were discussed and a consensus was reached about whether or not to include these papers in the review. Appendix A lists the 69 papers we included in the review.

\subsection{Coding the content of the papers}

In the final stage of the analysis a coding scheme was developed and the content of the 69 papers was coded against this coding scheme. We developed the coding scheme on the basis of discussions about which issues we considered important to understanding and assessing methodological issues in empirical $\mathrm{CIS}$ studies. These discussions were informed by the knowledge we had gained about the papers during the previous stages. The resulting coding scheme consisted of ten classifications, see Table 2 . An eleventh classification (the size of the CIS groups) was attempted but subsequently dropped because the group size could not be ascertained for many of the papers. For all but the classification of data types we coded the papers by selecting the one category that best matched the content of the paper; for the classification of 
data types we selected all the categories that matched the content of the paper. We acknowledge that the coding is our interpretation of the content of the papers. If different parts of a paper suggested different codings then we weighed the content of these parts against each other and decided on a coding.

To create a shared understanding of the coding scheme the authors initially coded 10 of the 69 papers and discussed their codings to reach consensus about the papers they had coded differently. Then the authors independently coded the remaining 59 papers. The agreement (Cohen's kappa) between the two authors was in the .61-.80 range ("substantial", according to Landis and Koch, 1977) for three of the classifications and in the .81-1.00 range ("almost perfect", according to Landis and Koch, 1977) for six of the classifications, see Table 2. For the last of the ten classifications the agreement could not be assessed with kappa, because the data were not nominal; the authors agreed about $81 \%$ of their codings for this classification. For all ten classification the two authors discussed their disagreements until a consensus was reached.

Table 2. The coding scheme

\begin{tabular}{lc}
\hline Categories & Kappa \\
\hline Purpose & .75
\end{tabular}

- Investigating the behavior of people engaged in a task that involves CIS activities

- Investigating the interaction between users and a CIS system

- Investigating the design of a CIS system

Level of investigation

- Exploratory (aimed at affirming existence or exemplifying constructs/relations)

- Analytic (aimed at providing coherent/rich descriptions)

- Confirmatory (aimed at testing a model or hypothesis)

Hypothesis?

- Hypotheses are explicitly presented

- Hypotheses are not presented

Comparative?

- An analysis of one CIS system, CIS team, or another entity

- A comparison of multiple CIS systems, CIS teams, or other entities

Participant type

- Professionals (persons with education and training in the work domain)

- Citizens (persons performing an activity in a leisure or other non-work context)

- Students (persons studying at a university or another educational institution)

- Other

Participant experience

- Novices (persons with little or no experience with an activity or system)

- Intermediate (persons with weeks or months of experience with an activity or system)

- Specialists (persons with years of experience with an activity or system)

- Other

Data collection

- Laboratory experiment (study under controlled conditions away from real environment)

- Field experiment (study in real environment while controlling certain conditions)

- Observation (study of real environment without controlling or deliberately disturbing it)

- Interview (talking with people one-on-one about an issue, typically face to face) 
- Focus group (talking with multiple people who are simultaneously present face to face)

- Survey (battery of fixed questions, often answered by selecting from fixed options)

- Action research (taking part in real environment to change and investigate it)

- Diaries (informants' own, possibly prompted, recordings of their behavior and reflections)

- Document analysis (collecting real documents from real environment)

- Log analysis (automated recording of people's actual behavior in real environment)

Data analysis

- Statistical testing (inferential statistics to test for correlations and differences in means)

- Descriptive statistics (describing data numerically or using graphs)

- Content analysis (categories are specified and the data are coded into these categories)

- Descriptive analysis (the data are described textually and examples are provided)

- Grounded theory (a bottom-up analysis consisting of open, axial, and selective coding)

- Other

Data types

- Behavior (how people use systems and perform activities)

- Experiences (how people experience and perceive systems and activities)

- Reasons (how people understand and reason about systems and activities)

- Outcomes (the quality and/or quantity of the product resulting from the activities)

Participant count

- Number of participants, summed across studies if the paper contains multiple studies

Note: ${ }^{\text {a }} \mathrm{A}$ kappa value could not be calculated because the participant count is not a nominal variable. We instead report the percentage of the papers for which the authors agreed in their coding.

\section{Review results}

The 69 reviewed papers were published between 1993 and 2017 with a increasing trend for all but the last five-year period: 4 (1993-97), 6 (1998-2002), 17 (2003-07), 27 (2008-2012), and 15 (2013-2017). CIS papers published 2013-17 were likely underrepresented in our sample because we selected the papers for the review by backward chaining from already published sources. In terms of outlet, the papers were from 16 different journals, 21 different conference series, and 1 book. The large number of outlets illustrates that $\mathrm{CIS}$ is a cross-disciplinary area, which may suggest methodological variety.

\subsection{Level of investigation}

We distinguished between three levels of investigation, see Table 3 . The majority of the reviewed papers were exploratory in that they aimed at affirming the existence of CIS phenomena or exemplifying constructs or relations that entered into CIS. For example, O'Day and Jeffries (1993) studied regular clients of professional search intermediaries and found that the clients acted as intermediaries themselves, sharing the information they had received and often doing it in collaborative settings that allowed for ensuring that the shared information was understood. Until 2001 all the reviewed papers were exploratory. The first analytic paper was Shapira et al. (2001), who investigated whether providing incentives in an information retrieval system motivated users to contribute evaluations of the information items to assist other users with similar needs. They found that rather inexpensive incentives produced modest but significant increases in cooperative behavior. The only confirmatory paper was Tamine and Soulier (2015), who aimed to test the hypotheses that the collaborators' behaviors were complementary 
with respect to division-of-labor policies and that differences in the collaborators' behavior represented complementarity signals. While we consider this paper confirmatory, it is noteworthy that the authors did not report whether the hypotheses were confirmed. Apart from Tamine and Soulier (2015), none of the reviewed papers contained explicitly stated hypotheses.

Table 3. Levels of investigation

\begin{tabular}{lccccc}
\hline \multirow{2}{*}{ Level of investigation } & \multicolumn{2}{c}{ Comparative } & & Total & Percent \\
\cline { 2 - 3 } & Yes & No & & \\
\hline Exploratory & 7 & 33 & 40 & 58 \\
Analytic & 18 & 10 & 28 & 41 \\
Confirmatory & 1 & 0 & 1 & 1 \\
\hline
\end{tabular}

The large number of exploratory papers and the near absence of confirmatory papers indicate that the CIS papers rarely built on each other in a systematic manner. Rather than refining a preexisting CIS framework, the papers searched for insights that might inform the future construction of a unifying CIS framework. The papers were instead systematic in a manner restricted to the internal setup of the individual study. For $26(38 \%)$ of the papers this setup involved comparison. For example, the papers compared the CIS behavior of teams in different work contexts (Reddy and Jansen, 2008), compared CIS in leisure and work contexts (Elbeshausen et al., 2015), compared CIS systems with baseline search systems (Freyne et al., 2004), compared the CIS behavior of co-located and remotely located collaborators (González-Ibánez et al., 2013), and compared the performance of collaborating pairs of users with that of users working individually (Lazonder, 2005). Comparison occurred in papers at all three levels of investigation (Table 3), thereby showing that it was used for exploring variety as well as for examining causality.

\subsection{Methods of data collection}

The top-three methods of data collection in the reviewed CIS studies were lab experiments, observation, and surveys, see Table 4 . As much as $78 \%$ of the studies employed one of these three methods. Lab experiments comprised 22 of the 24 studies that investigated interaction, 4 of the 6 studies that investigated design, and 4 of the 39 studies that investigated behavior. The other data-collection methods were near exclusively used when investigating behavior. Overall, $57 \%$ of the papers investigated behavior, $35 \%$ investigated interaction, and only $9 \%$ investigated design.

Table 4. Data-collection methods and their distribution on study purposes

\begin{tabular}{lcccccc}
\hline Data collection & \multicolumn{3}{c}{ Purpose } & Total & Percent \\
\cline { 2 - 4 } & Behavior & Interaction & Design & & \\
\hline Lab experiment & 4 & 22 & 4 & 30 & 43 \\
Observation & 13 & 0 & 0 & 13 & 19 \\
Survey & 10 & 0 & 1 & 11 & 16 \\
Interview & 4 & 2 & 0 & 6 & 9 \\
Field experiment & 4 & 0 & 1 & 5 & 7 \\
Diaries & 2 & 0 & 0 & 2 & 3
\end{tabular}




\begin{tabular}{llllll} 
Log analysis & 1 & 0 & 0 & 1 & 1 \\
Document analysis & 1 & 0 & 0 & 1 & 1 \\
Action research & 0 & 0 & 0 & 0 & 0 \\
Focus group & 0 & 0 & 0 & 0 & 0 \\
\hline
\end{tabular}

The typical lab experiment investigated the interaction between users and a specific CIS system. For example, Morris and Horvitz (2007) studied how the SearchTogether prototype facilitated collaboration among users during web searching. Seven pairs of users spent 20 minutes looking for information about a topic of mutual interest, including the planning of upcoming joint travel. The two users in a pair were seated in the same room, facing opposite walls, and instructed to pretend that they were at different locations to simulate remote collaboration. To maintain awareness of their collaborator's activities the users frequently turned to the query history in SearchTogether. They also used the instant-messaging feature to collaborate on their search task. As already mentioned the lab experiments also included the majority of the papers that focused primarily on the features of CIS systems (i.e., the papers investigating design). For example, Isenberg and Fisher (2009) described the user interface of Cambiera, a tabletop CIS system for supporting small groups of intelligence analysts in reconstructing stories from large amounts of data. In addition to the system description, the paper also reported from an initial usability evaluation. The evaluation involved three sessions of about 40 minutes. While the users appeared to understand Cambiera's collaborative features, they were not able to use them effectively because the restricted size of the tabletop interface meant that the opened documents were often on top of each other. Brief sessions, pretence, and small groups were common to the lab experiments. Specifically, the group size ranged from two to four users. It may be surprising that 15 (50\%) of the lab experiments were exploratory rather than analytic or confirmatory. The observation studies displayed a similarly even split between exploratory and analytic papers.

All 13 observation studies investigated people's behavior when they engaged in CIS. The people studied in these papers might use various CIS tools but the focus of the papers was the broader issues of how people find and make sense of information in the context of their collaborative activities. For example, Bruce et al. (2003) compared two design teams with respect to how the team members sought and used information. Both teams consisted of about ten persons, who were observed during work activities, especially team meetings. While the work context for the two teams was distinctly different, their information behavior was similar in its reliance on direct communication among people. An important activity in both teams was weekly meetings to identify and discuss information needs in a collaborative forum. The observation studies investigated collaborative activities that extended over prolonged periods, for example Hertzum (2002) observed a multi-year design project and Reddy and Spence (2008) observed a hospital department that was in operation around the clock. For this reason alone the size of the groups varied over the course of the activity but they tended to number ten or more people. While all these people were involved in CIS incidents, the individual CIS incident merely involved a subset of the group members. In addition, the investigated CIS incidents were often brief: the selection of an information source (Hertzum, 2002), the situations that triggered collaborative as opposed to individual information seeking (Reddy and Spence, 2008), and so forth. Thus, it is not straightforward to conclude whether the observation studies differed from the lab experiments as regards the duration of CIS incidents and the size of $\mathrm{CIS}$ groups. They did, however, differ in their focus on co-located versus remote situations. Whereas many of the lab experiments concerned CIS systems that enabled remotely located collaborators to seek information together, all but one (Twidale and Nichols, 1996) of the observation studies were about the CIS behavior of collaborators who were co-located at least part of the time. 
The surveys were predominantly exploratory (10 of 11 papers), non-comparative (10 of 11 papers), and investigating behavior (10 of 11 papers). For example, Morris (2013) surveyed whether the respondents had ever collaborated with others to search the web. The finding that $65 \%$ of the respondents had engaged in collaborative web searches indicated the prevalence of $\mathrm{CIS}$, especially among the younger respondents. Groups of two (31\%), three (23\%), and four (24\%) collaborators dominated; only $22 \%$ of the respondents had been in CIS groups of five or more collaborators. For the majority of the searches the groups had not been co-located. None of the surveys aimed to validate a model about what constructs that affected CIS behavior and how such constructs were interrelated. Instead, the surveys explored what kinds of CIS activities people engaged in, what tools they used, what barriers they experienced, and so forth. The response rate was reported for only five of the surveys: 16\% (Morris, 2013), 28\% (Morris, 2008), 46\% (Böhm et al., 2014), 47\% (Spence et al., 2005), and 54\% (Hertzum, 2010). The study by Hyldegård (2009b) was special because the ten survey participants were simultaneously involved in other study activities; all ten participants took the survey. Response rates were not available for the five remaining surveys because the respondents were recruited through crowdsourcing, mailing lists, and other means that masked who received the survey, and how many. The uncertainty about who received the surveys and the low response rate for several of them emphasize their exploratory nature. The only analytic survey (Hertzum, 2010) investigated breakdowns in CIS in a healthcare context and found that most of the breakdowns occurred during the collaborative grounding of information that was known to some of the collaborators - but remained unknown or unclear to those who were to act on it.

The interview studies provided access to the participants' accounts of their CIS activities and their thoughts about these activities. In all but one of these studies the participants were interviewed about $\mathrm{CIS}$ activities that predated the participants' recruitment for the study. For example, Given and Willson (2015) interviewed humanities scholars about their research practices to investigate the role of CIS in these practices, finding "a lack of group-based information seeking practices within collaborative research practices" (p. 139). As this study illustrated, the participants' practices might turn out to be thin on CIS. To circumvent this concern Kelly and Payne (2014) had the recruited participants use a specified CIS system (Coagmento or Diigo) for satisfying a self-selected information need before they were interviewed. The participants installed the CIS system on their own computer and used the system during their own time. That is, Kelly and Payne (2014) extended their interviews with elements of a field experiment. Relatedly, interviews were a frequent subcomponent of observation studies in addition to being the primary method of data collection in six papers.

The field experiments aimed to combine the experimental control normally confined to lab settings with the validity of conducting studies in naturalistic settings. Four of the five field experiments concerned $\mathrm{CIS}$ in elementary education and were conducted in the classroom. For example, Knight and Mercer (2015) had groups of two or three pupils search for answers to questions about role models. The groups that engaged the most in reasoned discussion during their searches were most successful in correctly answering the questions. Two papers (Hyldegård, 2006, 2009a) were based on diaries to collect longitudinal data about the user experience associated with university students' CIS during collaborative project assignments. The diary studies concerned how the user experience and CIS behavior evolved in relation to the progression of the project assignments and, thus, served to contextualize CIS in the task that caused it. Continuing the focus on CIS in educational settings, Zhou and Stahl (2007) made a log analysis of CIS in an online math forum for secondary-education students. The log data were at a level of detail that allowed for analyzing the conversational turns taken by the groups of participants in exploring and making collaborative sense of the math problems. In addition to the math problem-solving the participants sometimes went off topic and socialized. From the perspective of building ties and group commitment such socialization was an important part of CIS. Prekop (2002) made a document analysis of $\mathrm{CIS}$ in a military working group. The input to the analysis was the minutes of the working-group meetings. 
These minutes enabled an analysis of the CIS roles formally assigned to participants and informally adopted by them. Finally, it should be noted that none of the 69 reviewed papers were action research or focus group studies.

\subsection{Study participants}

The participants in the reviewed studies were fairly evenly distributed across levels of experience: 19 (28\%) intermediate, 17 (25\%) novice, 13 (19\%) specialist, and 20 (29\%) other. The 20 studies in the 'other' group either did not report the participants' experience or involved a mix of specialists, intermediates, and novices. In several cases CIS systems intended for users with mixed experience were studied with novices as users, but mostly the study participants' experience matched that of the intended users. The reviewed papers provide ample evidence of $\mathrm{CIS}$ at all three levels of participant experience, thereby verifying the need for investigating $\mathrm{CIS}$ for novice, intermediate as well as specialist participants. In educational settings (e.g., Kuiper et al., 2009) the participants were learners, who almost by definition lack experience. In corporate settings (e.g., Ehrlich and Cash, 1994) the participants were typically more experienced. In leisure settings (e.g., Yue et al., 2012) the participants spanned multiple levels of experience, including intermediate. Unsurprisingly, the specialists were always professionals and the novices predominantly students. Overall, students (45\%) were a slightly more common participant type than professionals (41\%); the remaining $14 \%$ of the papers had the participant type 'other'.

Table 5 shows how the participants' experience was distributed across the methods of data collection and gives the median number of participants for each data-collection method. We report the median, rather than the mean, to avoid that extreme values skew the results (see Appendix A for the number of participants in the individual studies). The log analyses and surveys involved substantially more participants than the other studies. For document analyses, lab experiments, field experiments, interviews, and observation the median number of participants was between 18 and 28 , a fairly narrow range. Different methods of data collection were used in studies involving specialists and novices. Specialists, but not novices, participated in interviews, surveys, and document analyses; novices, but not specialists, participated in lab experiments, field experiments, and log analyses. Observation was the only method used in studies of both specialists (e.g., Hansen and Järvelin, 2005) and novices (e.g., Twidale and Nichols, 1996).

Table 5. Study participants

\begin{tabular}{lccccc}
\hline Data collection & \multicolumn{4}{c}{ Participant experience } & Median number \\
\cline { 2 - 5 } & Specialist & Intermediate & Novice & Other & \\
\hline of participants ${ }^{\text {a }}$
\end{tabular}

${ }^{a}$ Studies not reporting the number of participants were excluded from the calculations of the median, see Appendix A. 


\subsection{Types of data}

As many as 66 (96\%) of the reviewed papers provided data about CIS behavior, that is about the collaborative activities people engaged in to seek and make sense of information. In addition, 35 (51\%) papers provided data about reasons, that is about the cognitive aspects of CIS; 28 (41\%) papers provided data about experiences, that is about the affective aspects of CIS; and $21(30 \%)$ papers provided data about the outcomes of CIS. The studied behavioral aspects included, among others, the critical tasks involved in scientists' CIS (Blake and Pratt, 2006), the activities performed by users to remain aware of remotely located collaborators when using CIS systems (Shah, 2013), and the automatic mining of patterns in users' actions to enable CIS systems to identify users with different CIS roles (Soulier et al., 2014). Twelve papers provided data about behavior only (e.g., Diamadis and Polyzos, 2004) but the majority of the papers combined data about behavior with data about at least one of reasons, experiences, and outcomes.

The studied reasons included consulting colleagues because they were more experienced (Fidel et al., 2004), liking a CIS system because access to collaborators' search queries was considered useful (Tao and Tombros, 2013), sharing information with others because these particular pieces of information were deemed important to a joint task (Paul and Reddy, 2010), directing one's searches toward a particular topic because a CIS tool made it visible that collaborators were attending to that topic (Capra et al., 2013), choosing to interact with other researchers because they cited papers similar to the ones cited by the user (Farooq et al., 2009), and shifting from individual to collaborative information behavior because problem complexity increased (Reddy and Jansen, 2008). Collectively these reasons provided explanations and rationales for a variety of CIS behaviors and system assessments.

The studied experiences showed that CIS was for the most part experienced favorably. For example, Spence et al. (2005) found that the surveyed researchers experienced collaborative searching as easier, quicker, and leading to more relevant information than individual searching. Relatedly, Church et al. (2012) found that the top motivator for mobile search in social settings was to satisfy the survey respondents' curiosity whereas alleviating boredom was the least common motivator. However, it has also been documented how student collaborators experienced uncertainty, frustration, stress, and disappointment in relation to the information-seeking activities of their evolving projects (Hyldegård, 2006, 2009a). To the extent that experiences were studied along with outcomes, the studies tacitly assumed that the relation between the two was one of experiences following from outcomes. Only one study investigated the opposite direction of influence: experiential factors giving rise to CIS outcomes. In this study González-Ibánez and Shah (2014) found that pairs of collaborators who had both been induced a negative affective state subsequently solved more CIS tasks correctly than pairs in which one or both collaborators had been induced a positive affective state. The authors speculated that negative affective states might be associated with more careful evaluation of retrieved information.

The studied outcomes included the precision and recall of the searches performed under different $\mathrm{CIS}$ conditions (González-Ibánez et al., 2013; Joho et al., 2008; Smeaton et al., 2007), the number of facts discovered by users seeking information online either collaboratively or individually (Evans et al., 2010), and the number of correct answers to tasks investigated through collaborative web searching (Amershi and Morris, 2008). These outcome measures were all from lab experiments and rather restricted in their conception of CIS outcomes. In contrast, Kuiper et al. (2009) measured outcomes as the improvement in the students' knowledge about the topic of the searches from before to after the field experiment and Hertzum (2010) analyzed adverse medication incidents in hospitals to determine the CIS breakdowns that caused the incidents. In terms of examples of the downstream outcomes of CIS, Church et al. (2012, p. 
398) documented that social mobile search influenced decisions (e.g., "We decided not to take the car"), plans (e.g. "We will read the book"), actions (e.g., "we booked the travel"), and purchases (e.g., "We had to buy an umbrella").

Table 6 shows the distribution of the four data types onto the methods of data collection. Data about experiences were mainly collected through surveys and lab experiments; surprisingly few interview studies contained data about experiences. The methods that provided data about outcomes were mainly surveys, lab experiments, and field experiments. Conversely, data about reasons were spread across many methods of data collection. The average number of data types per study varied from 1.00 (log analyses) to 2.55 (surveys), thereby suggesting a more comprehensive coverage of types of CIS phenomena in surveys, lab experiments, and interviews (Table 6). Only three papers provided all four types of data: one survey (Church et al., 2012) and two lab experiments (Evans et al., 2010; Joho et al., 2008).

Table 6. Data types distributed onto methods of data collection

\begin{tabular}{|c|c|c|c|c|c|c|}
\hline \multirow[t]{2}{*}{ Data collection } & \multicolumn{4}{|c|}{ Data types } & \multirow{2}{*}{$\begin{array}{c}\text { Total } \\
\text { studies }\end{array}$} & \multirow{2}{*}{$\begin{array}{l}\text { Data types } \\
\text { per study }\end{array}$} \\
\hline & Behavior & Experiences & Reasons & Outcomes & & \\
\hline Survey & 11 & 5 & 9 & 3 & 11 & 2.55 \\
\hline Lab experiment & 28 & 18 & 11 & 14 & 30 & 2.37 \\
\hline Interview & 6 & 2 & 5 & 1 & 6 & 2.33 \\
\hline Diaries & 2 & 2 & 0 & 0 & 2 & 2.00 \\
\hline Document analysis & 1 & 0 & 1 & 0 & 1 & 2.00 \\
\hline Field experiment & 5 & 0 & 1 & 3 & 5 & 1.80 \\
\hline Observation & 12 & 1 & 8 & 0 & 13 & 1.62 \\
\hline Log analysis & 1 & 0 & 0 & 0 & 1 & 1.00 \\
\hline
\end{tabular}

\subsection{Methods of data analysis}

The CIS studies were evenly split between 28 qualitative analyses (description, grounded theory) and 27 quantitative analyses (statistical testing, descriptive statistics) with content analysis as an intermediate category, see Table 7. We reiterate that we coded the primary method of data analysis. Specifically, all studies contained elements of description as a supplementary method. For all methods the analyzed data were spread across the data types (Table 7).

Description ranged from rich narratives in observation studies (Fidel et al., 2004) to qualitative accounts of lab experiments (Aneiros and Estivill-Castro, 2005). A common characteristic of these studies was that they contained neither statistics nor coding of the data into categories. Statistical testing was a more uniform category of studies, 14 (70\%) of which were lab experiments (e.g., Shapira et al., 2001). Content analysis was used for categorizing the data, characterizing the content of the categories, and determining the number of elements in each category. Like description, content analysis was used for analyzing data collected with a variety of methods, including five lab experiments (e.g. Shah, 2013) and two interview studies (e.g., Kelly and Payne, 2014). Descriptive statistics mostly served as a supplementary method of data analysis; it was the primary method in only seven studies, including an observation study (Hansen and Järvelin, 2005). Grounded theory was used to categorize the collected data in a bottom-up manner, thereby aiming - through categorizing still more data and revising previously created categories - to build a coherent understanding of the data (e.g., Given and Willson, 2015). Notably, the parts of grounded 
theory intended to govern data collection (e.g., theoretical saturation, see Glaser and Strauss, 1967) were not mentioned in the reviewed studies, which merely employed grounded theory during data analysis.

Table 7. Methods of data analysis, and the types of data analyzed

\begin{tabular}{lccccccc}
\hline Data analysis & \multicolumn{4}{c}{ Data types } & & Total & Percent \\
& \cline { 2 - 5 } & Behavior & Experiences & Reasons & Outcomes & & studies \\
\hline Description & 21 & 5 & 12 & 2 & 23 & 33 \\
Statistical testing & 19 & 12 & 7 & 12 & 20 & 29 \\
Content analysis & 13 & 4 & 6 & 4 & 13 & 19 \\
Descriptive statistics & 7 & 3 & 5 & 3 & 7 & 10 \\
Grounded theory & 5 & 3 & 5 & 0 & 5 & 7 \\
Other & 1 & 1 & 0 & 0 & 1 & 1 \\
\hline
\end{tabular}

\section{Discussion}

Methodological issues influence CIS studies in multifarious ways. In the following we summarize the many details of this review in main findings, discuss model building as its major implication, and account for the limitations of this review.

\subsection{Methodological CIS issues}

The present review of methodological issues in empirical CIS studies can be summarized in six main findings. First, $\mathrm{ClS}$ research is dominated by exploratory studies. Only one of the 69 reviewed papers is confirmatory. We see this as indicating that $\mathrm{CIS}$ is a young research area that is still searching for its main concepts and models. In the absence of authoritative models each CIS study tends to contribute empirical insights, which is commendable, but also to struggle to enrich previous research in a cumulative manner. The state of affairs is illustrated by the large number of studies that motivate a focus on CIS by noting that most models of information seeking assume that it is an activity performed by individual actors (e.g., Capra et al., 2013; Paul and Morris, 2011; Soulier et al., 2014). After 25 years of CIS research one could have hoped that studies were consistently motivated by more specific questions and distinctions than the observation that CIS phenomena exist. The development of a shared model or framework to which individual CIS studies can cumulatively contribute would be a major step forward for CIS research.

Second, the three most common methods of data collection in the reviewed studies are lab experiments (43\%), observation (19\%), and surveys (16\%). McGrath (1981) argues that these three methods achieve maximum precision in control and measurement, maximum realism of the context, and maximum generalizability with respect to populations, respectively. He goes on to argue that, unfortunately, these three desiderata are achieved at the expense of each other. Thus, the most common method of data collection in CIS studies lacks realism and generalizability, the second-most common method lacks precision and generalizability, and surveys lack precision and realism. Field experiments (7\% of the CIS studies) attempt to achieve both precision and realism but still at the expense of generalizability. Collectively CIS research appears to assign primacy to precision and be low on generalizability. In continuation of this finding CIS research is biased toward the fairly brief CIS activities that can be studied in the lab. 
Third, it is a methodological challenge that CIS activities extend over time and involve people who may be at different locations. For example, lab experiments are confined to fairly brief sessions and surveys capture snapshots and aggregates better than evolution. To investigate how $\mathrm{CIS}$ activities unfold over time we propose diary studies and observation even though they are demanding in participant motivation and researcher resources, respectively. Only two of the reviewed studies are diary studies. And none of them used contemporary means of experience sampling, such as prompting participants for information by sending them text messages at preset or randomly selected points in times (e.g., Bolger and Laurenceau, 2013). We specifically note a need for observation studies of remote CIS to understand better the situated ways in which real-world CIS activities unfold among people who are not face to face. Such studies call for multiple researchers to coordinate their observation sessions, for simultaneous video recordings at multiple sites, or for other inventive methods of data collection.

Fourth, the participants in the reviewed studies are a fairly even mix of novices, intermediates, and specialists. The participants' level of experience varies with the method of data collection, thereby suggesting that convenience has been a larger factor in the selection of participants for some methods (e.g., lab experiments) than others. In most of the studies of concrete CIS systems the participants' experience matches that of the intended users but it should be noted that none of the studies investigate the relation between $\mathrm{CIS}$ phenomena and the level of participant experience. With respect to group size Morris (2013) finds that $78 \%$ of CIS groups consist of 2-4 people. While the reviewed lab experiments involved CIS groups of that size, the group size appeared to be larger in the observation studies. In addition, the size of a CIS group may change over time because people dynamically enter and leave the group in response to the demands of its task. Longitudinal studies are needed to investigate the consequences of such dynamic group membership.

Fifth, while $96 \%$ of the reviewed papers provide data about CIS behavior, substantially fewer of them investigate the reasons (51\%), experiences (41\%), and outcomes (30\%) associated with CIS. Each of the reviewed papers provides data about an average of only 2.17 of the four types of data. As a consequence the interactions between CIS behavior and the associated reasons, experiences, and outcomes are not well-understood. It is for example not clear whether people enjoy CIS activities or largely perform them for utilitarian reasons. Aside from lab experiments, only seven studies investigate CIS outcomes. That is, we know little about the downstream effects of CIS. One pertinent, but largely unanswered, question concerns the conditions under which CIS leads to quality results that move real-world tasks toward successful completion.

Sixth, it remains a limitation of the reviewed studies that it is largely unknown in what ways the findings are specific to the studied people, tasks, and CIS systems. This limitation could, in part, be mitigated by providing more detail about study participants, task characteristics, and so forth in the individual study. To get beyond this partial solution the CIS community needs a shared framework that makes it possible to relate individual studies to each other in a more systematic manner and, thereby, use these relations to gain an understanding of how the findings of a study depend on the particulars of the study. In terms of unexploited possibilities we also note that action research was not used in any of the reviewed studies. The absence of action research may indicate a lack of knowledge among CIS researchers about how to do $\mathrm{CIS}$ effectively and efficiently, thereby discouraging research interventions to promote specified $\mathrm{CIS}$ practices.

\subsection{The major implication: model building}

We contend that the major implication of this review is its identification of the need for a shared model or framework to which individual CIS studies can cumulatively contribute. To support the CIS community 
in building such a model or framework we will consider two different models: a core model of the CIS process and a tentative model of the factors that give rise to $\mathrm{CIS}$.

When CIS studies propose models it is near exclusively process models (e.g., Blake and Pratt, 2006; Böhm et al., 2014; Evans and Chi, 2010; Hansen and Järvelin, 2005). Several of these models are detailed (with over 10 activities and over 20 inter-activity relations) but at an aggregate level CIS proceeds from need recognition through information seeking and collaborative grounding to information use and task completion, see Figure 3. We provide an aggregate-level model because we find that discussion and agreement about such a core model would be an important first step in enabling CIS studies to build more systematically on each other. The distinction between information seeking and collaborative grounding (a.k.a., sensemaking; Paul and Morris, 2011) is emphasized in several observation studies. For example, Hertzum (2002) found that the studied team of software engineers often delegated information-seeking activities to individuals or subgroups who subsequently reported back to the team, which then discussed and collaboratively grounded the retrieved information. Conversely, in some of the lab experiments information seeking and collaborative grounding are intermixed to the point of being indistinguishable because the timeframe for the entire CIS activity is compressed (e.g., Yue et al., 2012).

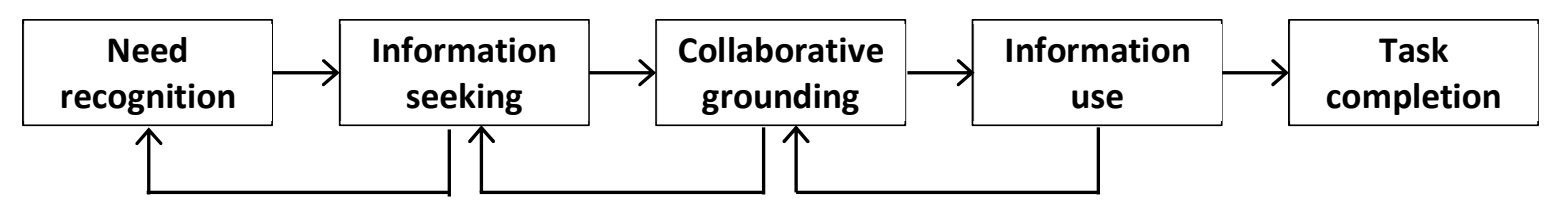

Figure 3. Core model of the CIS process

A few of the reviewed studies provide models that are not process models. For example, the model by Reddy and Jansen (2008) seeks to show the situational characteristics that trigger CIS. Their model proposes that people shift from individual to collaborative information seeking when their problems expand from simple to complex, when the number of actors involved in the task grows from single to multiple, and when the interactions among the actors evolve from direct to conversational. We appreciate the focus on the situational characteristics that trigger CIS but also think that the range of triggers may be substantially wider.

The theories of reasoned action (Fishbein and Ajzen, 1975) and planned behavior (Ajzen, 1991) provide a possible theoretical basis for a model of the factors that give rise to CIS. These theories distinguish between beliefs, attitudes, and behavioral intentions and maintain that beliefs govern attitudes and attitudes govern behavioral intentions. In addition, behavioral intentions are also influenced by social norms (Fishbein and Ajzen, 1975). On this basis we propose that people engage in CIS when it is consistent with their beliefs. More specifically, their beliefs are aggregated into an attitude that gives rise to a behavioral intention that, in turn, triggers CIS behavior (Figure 4). It is for future work to determine the concrete beliefs that give rise to CIS. Candidate beliefs might include perceiving CIS as useful, easy, and pleasant. Reasons for beliefs can potentially be found in people characteristics (one of the factors in the center box of Figure 1) such as self-efficacy and extroversion. We propose that tasks and CIS systems (the two other factors in the center box of Figure 1) influence CIS by moderating the influence of beliefs on attitude. Influential task characteristics may include complexity (Reddy and Jansen, 2008), importance (Agarwal et al., 2011), and urgency (Julien and Michels, 2004). Influential system characteristics may, for example, include the presence or absence of chat facilities (Joho et al., 2008) and awareness support (Morris and Horvitz, 2007). We also speculate that social norms for or against CIS moderate the influence of attitude on behavioral intention and that various contextual conditions facilitate, or otherwise 
moderate, the extent to which a behavioral intention leads to actual CIS behavior. Potential sources of social norms and facilitating conditions include workplaces and other organizational settings.

The model in Figure 4 is informed by the empirical studies in this review but they do not provide a basis from which a model can be systematically derived. We propose the model to stir interest in creating a cumulative basis for research on the triggers and barriers of CIS. The tentative model begins to ask a lot of needed questions: What are the important beliefs, task characteristics, and other constructs? How strongly do they influence behavioral intentions and actual CIS behavior? Why? Under which conditions? It is for future CIS research to answer these questions, or reject the model.

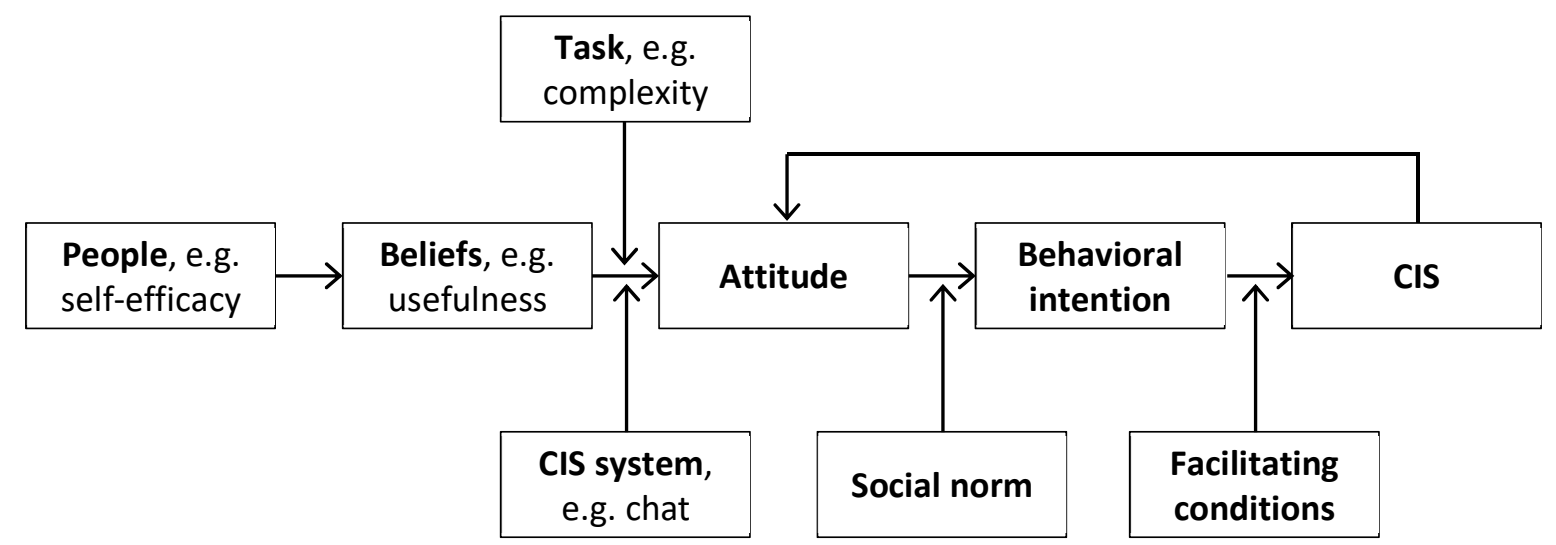

Figure 4. Tentative model of the factors that give rise to CIS

\subsection{Limitations}

Three limitations should be remembered in reading this review. First, we selected the papers for the review from the references of ten prominent CIS sources. This approach tends to miss the newest papers, which have not yet been cited. In addition, we excluded workshop papers because they are brief and biased toward somewhat informal studies, but we note that a number of CIS papers have been published at workshops. Second, we have proceeded from a bottom-up coding of the papers. While we achieved substantial agreement about the coding, we acknowledge that the codes are interpretations of the content of the papers. The coding of the types of data (behavior, experiences, reasons, outcomes) may, in particular, warrant independent replication. It should also be noted that a small subset of the reviewed studies employed multiple methods of data collection or data analysis. For these studies the coding merely captures the primary method. Third, we restricted the review to empirical studies. By leaving out conceptual papers the review may miss extant attempts at constructing CIS models and frameworks. Such attempts should, obviously, be merged into future empirical work aimed at building and assessing CIS models in a cumulative manner.

\section{Conclusion}

We have reviewed methodological issues in 69 empirical CIS studies to assess CIS research, guide future studies, and inspire further methodological discussion. In summary, we find that:

- CIS research is dominated by exploratory studies that rarely built on each other in a cumulative manner. While a number of the reviewed studies involve comparison, only one study is confirmatory. 
- Lab experiments, observation, and surveys are the prevalent methods of data collection. It is a key challenge that the methods struggle with investigating how CIS unfolds over time and across space.

- Study participants are fairly evenly distributed between novices, intermediates, and specialists. Studies of novices (in the lab) tend to involve smaller group sizes than studies of specialists.

- CIS behavior is investigated in all but three studies. Considerably fewer studies provide data about reasons, experiences, and outcomes. More data on outcomes appear especially desirable.

- The most common methods of data analysis are description, statistical testing, and content analysis. Collectively, the studies are evenly balanced between qualitative and quantitative analyses.

- The studies leave it largely unexplored in what ways their findings may be specific to the particular study setting. Relatedly, empirical CIS research appears low on generalizability.

These findings suggest the need for a shared model that provides a context for appraising the findings of individual CIS studies and cumulatively absorbs the findings of individual CIS studies. We hope the CIS community will embrace the undertaking of empirically building and refining such a model. As a modest contribution to this undertaking we have proposed a tentative model of the factors that give rise to $\mathrm{CIS}$.

\section{Appendix A: The 69 reviewed papers}

\begin{tabular}{llllc}
\hline Paper & Data collection & Data analysis & Data types & Participants \\
\hline Amershi and Morris (2008) & Lab experiment & Statistical testing & B, E, O & 43 \\
Aneiros and Estivill-Castro (2005) & Lab experiment & Description & B, E & 50 \\
Blake and Pratt (2006) & Observation & Description & B, R & 19 \\
Bruce et al. (2003) & Observation & Description & B, R & 19 \\
Böhm et al. (2014) & Survey & Descriptive stats & B, R & 24 \\
Capra et al. (2010) & Interview & Content analysis & B, R & 30 \\
Capra et al. (2012) & Lab experiment & Descriptive stats & B, E, R & 14 \\
Capra et al. (2013) & Lab experiment & Content analysis & B, R & 11 \\
Church et al. (2012) & Survey & Descriptive stats & B, E, R, O & 193 \\
Diamadis and Polyzos (2004) & Lab experiment & Statistical testing & B & 40 \\
Ehrlich and Cash (1994) & Observation & Description & B, R & - \\
Elbeshausen et al. (2015) & Survey & Descriptive stats & B, R & - \\
Evans and Chi (2010) & Survey & Description & B, R & 300 \\
Evans et al. (2010) & Lab experiment & Descriptive stats & B, E, R, O & 8 \\
Farooq et al. (2009) & Survey & Statistical testing & B, E, R & 301 \\
Fidel et al. (2004) & Observation & Description & B, R & 10 \\
Freyne et al. (2004) & Lab experiment & Description & B, O & 92 \\
Given and Willson (2015) & Interview & Grounded theory & B, E, R & 20 \\
González-Ibánez et al. (2011) & Lab experiment & Statistical testing & E, O & 30 \\
González-Ibánez et al. (2013) & Lab experiment & Statistical testing & B, E, O & 60 \\
González-Ibánez and Shah (2014) & Lab experiment & Statistical testing & B, E, O & 90
\end{tabular}




\begin{tabular}{|c|c|c|c|c|}
\hline Gorman et al. (2002) & Observation & Description & B & - \\
\hline Hansen and Järvelin (2005) & Observation & Descriptive stats & B & 9 \\
\hline Hertzum (2002) & Observation & Content analysis & $B, R$ & 17 \\
\hline Hertzum (2010) & Survey & Content analysis & $B, R, O$ & 232 \\
\hline Hertzum et al. (2002) & Interview & Description & B & - \\
\hline Hertzum and Reddy (2015) & Observation & Description & B & 193 \\
\hline Hyldegård (2006) & Diaries & Content analysis & $B, E$ & 5 \\
\hline Hyldegård (2009a) & Diaries & Content analysis & $B, E$ & 10 \\
\hline Hyldegård (2009b) & Survey & Description & $B, E, R$ & 10 \\
\hline Isenberg and Fisher (2009) & Lab experiment & Other & $B, E$ & 5 \\
\hline Jetter et al. (2011) & Lab experiment & Statistical testing & $B, E, R$ & 79 \\
\hline Joho et al. (2008) & Lab experiment & Statistical testing & $B, E, R, O$ & 24 \\
\hline Kelly and Payne (2014) & Interview & Content analysis & $B, E, R$ & 16 \\
\hline Knight and Mercer (2015) & Field Experiment & Content analysis & $\mathrm{B}, \mathrm{O}$ & 8 \\
\hline Knight and Mercer (2017) & Field Experiment & Content analysis & $B, R, O$ & 8 \\
\hline Kuiper et al. (2009) & Field Experiment & Statistical testing & $\mathrm{B}, \mathrm{O}$ & 97 \\
\hline Large et al. (2002) & Field Experiment & Statistical testing & B & 44 \\
\hline Lazonder (2005) & Lab experiment & Content analysis & $\mathrm{B}, \mathrm{O}$ & 25 \\
\hline Maekawa et al. (2006) & Lab experiment & Statistical testing & $B, E$ & 18 \\
\hline Mitrelis et al. (2008) & Lab experiment & Description & $E, R$ & 9 \\
\hline Morris (2008) & Survey & Description & B & 204 \\
\hline Morris (2013) & Survey & Statistical testing & $B, E, R$ & 167 \\
\hline Morris and Horvitz (2007) & Lab experiment & Descriptive stats & $\mathrm{B}, \mathrm{O}$ & 14 \\
\hline Morris et al. (2006) & Lab experiment & Statistical testing & $B, E, O$ & 16 \\
\hline Morris et al. (2008) & Survey & Statistical testing & $\mathrm{B}, \mathrm{O}$ & 30 \\
\hline Morris et al. (2010) & Lab experiment & Description & $B, E, R$ & 42 \\
\hline O'Day and Jeffries (1993) & Interview & Description & $B, R$ & 15 \\
\hline Paul and Morris (2009) & Lab experiment & Description & $B, R$ & 18 \\
\hline Paul and Morris (2011) & Lab experiment & Content analysis & $\mathrm{B}, \mathrm{E}$ & 36 \\
\hline Paul and Reddy (2010) & Observation & Grounded theory & $B, E, R$ & 12 \\
\hline Poltrock et al. (2003) & Interview & Description & $B, R, O$ & 20 \\
\hline Prekop (2002) & Doc analysis & Grounded theory & $B, R$ & 28 \\
\hline Reddy and Jansen (2008) & Observation & Description & $B, R$ & - \\
\hline Reddy et al. (2008) & Lab experiment & Description & $\mathrm{B}, \mathrm{E}$ & 20 \\
\hline Reddy and Spence (2008) & Observation & Grounded theory & $B, R$ & - \\
\hline Shah (2013) & Lab experiment & Content analysis & B & 84 \\
\hline Shah and González-Ibáñez (2012) & Lab experiment & Statistical testing & $B, E, O$ & 60 \\
\hline
\end{tabular}


Shapira et al. (2001)

Smeaton et al. (2007)

Soulier et al. (2014)

Spence and Reddy (2007)

Spence et al. (2005)

Tamine and Soulier (2015)

Tao and Tombros (2013)

Twidale et al. (1995)

Twidale and Nichols (1996)

Yue et al. (2012)

Zhou and Stahl (2007)

$\begin{array}{lllc}\text { Lab experiment } & \text { Statistical testing } & \text { B, R } & 162 \\ \text { Lab experiment } & \text { Statistical testing } & \text { B, R, O } & 16 \\ \text { Lab experiment } & \text { Statistical testing } & \text { B, O } & 140 \\ \text { Observation } & \text { Description } & \text { B } & 25 \\ \text { Survey } & \text { Statistical testing } & \text { B, E, R } & 70 \\ \text { Lab experiment } & \text { Statistical testing } & \text { B, O } & 150 \\ \text { Lab experiment } & \text { Grounded theory } & \text { B, E, R } & 24 \\ \text { Field Experiment } & \text { Description } & \text { B } & 20 \\ \text { Observation } & \text { Description } & - & - \\ \text { Lab experiment } & \text { Content analysis } & \text { B } & 14 \\ \text { Log analysis } & \text { Description } & \text { B } & 200\end{array}$

Note: $\mathrm{B}$ - behavior, $\mathrm{E}$ - experiences, $\mathrm{R}$ - reasons, $\mathrm{O}$ - outcomes

\section{References}

Agarwal, N.K., Xu, Y. and Poo, D.C.C. (2011), "A context-based investigation into source use by information seekers", Journal of the American Society for Information Science and Technology, Vol. 62 No. 6, pp. 1087-1104.

Ajzen, I. (1991), "The theory of planned behavior", Organizational Behavior and Human Decision Processes, Vol. 5 No. 2, pp. 179-211.

Amershi, S. and Morris, M.R. (2008), "CoSearch: A system for co-located collaborative web search", in Proceedings of the CHI2008 Conference on Human Factors in Computing Systems, ACM Press, New York, pp. 1647-1656.

Aneiros, M. and Estivill-Castro, V. (2005), "Usability of real-time unconstrained www-co-browsing for educational settings", in Proceedings of the WI2005 Conference on Web Intelligence, IEEE Computer Society, Washington, DC, pp. 105-111.

Blake, C. and Pratt, W. (2006), "Collaborative information synthesis I: A model of information behaviors of scientists in medicine and public health", Journal of the American Society for Information Science and Technology, Vol. 57 No. 13, pp. 1740-1749.

Bolger, N. and Laurenceau, J.-P. (2013), Intensive longitudinal methods: An introduction to diary and experience sampling research, Guilford Press, New York.

Bruce, H., Fidel, R., Pejtersen, A.M., Dumais, S., Grudin, J. and Poltrock, S. (2003), "A comparison of the collaborative information retrieval behaviors of two design teams", New Review of Information Behaviour Research, Vol. 4, pp. 139-153.

Böhm, T., Klas, C.-P. and Hemmje, M. (2014), "Collaborative information seeking in professional worksettings: A study of equipment utilization", Datenbank Spektrum, Vol. 14 No. 1, pp. 29-38.

Capra, R., Chen, A.T., Hawthorne, K., Arguello, J., Shaw, L. and Marchionini, G. (2012), "Design and evaluation of a system to support collaborative search", Proceedings of the Association for Information Science and Technology, Vol. 49 No. 1, pp. 1-10.

Capra, R., Chen, A.T., McArthur, E. and Davis, N. (2013), "Searcher actions and strategies in asynchronous collaborative search", Proceedings of the Association for Information Science and Technology, Vol. 50 No. 1, pp. 1-10. 
Capra, R., Marchionini, G., Velasco-Martin, J. and Muller, K. (2010), "Tools-at-hand and learning in multisession, collaborative search", in Proceedings of the CHI2010 Conference on Human Factors in Computing Systems, ACM Press, New York, pp. 951-960.

Case, D.O. and Given, L.M. (2016), Looking for information: A survey of research on information seeking, needs, and behavior (4th ed.), Emerald, Bingley, UK.

Church, K., Cousin, A. and Oliver, N. (2012), "I wanted to settle a bet! - Understanding why and how people use mobile search in social settings", in Proceedings of the MobileCHI2012 Conference on HumanComputer Interaction with Mobile Devices and Services, ACM Press, New York, pp. 393-402.

Cohen, J. (1960), "A coefficient of agreement for nominal scales", Educational and Psychological Measurement, Vol. 20 No. 1, pp. 37-46.

Diamadis, E.T. and Polyzos, G.C. (2004), "Efficient cooperative searching on the web: System design and evaluation", International Journal of Human-Computer Studies, Vol. 61 No. 5, pp. 699-724.

Ehrlich, K. and Cash, D. (1994), "Turning information into knowledge: Information finding as a collaborative activity", in Schnase, J.L., Leggett, J.J., Furuta, R.K. and Metcalfe, J. (Eds.), Proceedings of the First Annual Conference on the Theory and Practice of Digital Libraries, Texas A\&M University, College Station, TX, pp. 119-125.

Elbeshausen, S., Mandl, T. and Womser-Hacker, C. (2015), "Collaborative information seeking in the context of leisure and work task situations: A comparison of three empirical studies", in Hansen, P., Shah, S. and Klas, C.-P. (Eds.), Collaborative Information Seeking: Best Practices, New Domains and New Thoughts, Springer, Switzerland, pp. 73-98.

Evans, B.M. and Chi, E.H. (2010), "An elaborated model of social search", Information Processing \& Management, Vol. 46 No. 6, pp. 656-678.

Evans, B.M., Kairam, S. and Pirolli, P. (2010), "Do your friends make you smarter?: An analysis of social strategies in online information seeking", Information Processing \& Management, Vol. 46 No. 6, pp. 679-692.

Farooq, U., Ganoe, C.H., Carroll, J.M. and Giles, C.L. (2009), "Designing for e-science: Requirements gathering for collaboration in CiteSeer", International Journal of Human-Computer Studies, Vol. 67 No. 4, pp. 297-312.

Fidel, R., Bruce, H., Pejtersen, A.M., Dumais, S., Grudin, J. and Poltrock, S. (2000), "Collaborative information retrieval (CIR)", New Review of Information Behaviour Research, Vol. 1, pp. 235-247.

Fidel, R., Pejtersen, A.M., Cleal, B. and Bruce, H. (2004), "A multidimensional approach to the study of human-information interaction: A case study of collaborative information retrieval", Journal of the American Society for Information Science and Technology, Vol. 55 No. 11, pp. 939-953.

Fishbein, M. and Ajzen, I. (1975), Belief, attitude, intention and behavior: An introduction to theory and research, Addison-Wesley, Reading, MA.

Foster, J. (2006), "Collaborative information seeking and retrieval", in Cronin, B. (Ed.), Annual Review of Information Science and Technology (Vol. 40), Information Today, Medford, NJ, pp. 329-356.

Freyne, J., Smyth, B., Coyle, M., Balfe, E. and Briggs, P. (2004), "Further experiments on collaborative ranking in community-based web search", Artificial Intelligence Review, Vol. 21 No. 3, pp. 229-252.

Given, L.M. and Willson, R. (2015), "Collaboration, information seeking, and technology use: A critical examination of humanities scholars' research practices", in Hansen, P., Shah, C. and Klas, C.-P. (Eds.), Collaborative Information Seeking: Best Practices, New Domains and New Thoughts, Springer, Berlin, pp. 139-164.

Glaser, B.G. and Strauss, A.L. (1967), The discovery of grounded theory: Strategies for qualitative research, Aldine de Gruyter, New York.

Golovchinsky, G., Qvarfordt, P. and Pickens, J. (2009), "Collaborative information seeking", IEEE Computer, Vol. 42 No. 3, pp. 47-51. 
González-Ibánez, R., Haseki, M. and Shah, S. (2013), "Let's search together, but not too close! An analysis of communication and performance in collaborative information seeking", Information Processing \& Management, Vol. 49 No. 5, pp. 1165-1179.

González-Ibánez, R. and Shah, S. (2014), "Performance effects of positive and negative affective states in a collaborative information seeking task", in Baloian, N., Burstein, F., Ogata, H., Santoro, F. and Zurita, G. (Eds.), Proceedings of the CRIWG2014 Conference on Collaboration and Technology, Springer, Switzerland, pp. 153-168.

González-Ibánez, R., Shah, S. and Córdova-Ribio, N. (2011), "Smile! Studying expressivity of happiness as a synergic factor in collaborative information seeking", Proceedings of the Association for Information Science and Technology, Vol. 48 No. 1, pp. 1-10.

Gorman, P., Lavelle, M., Delcambre, L. and Maier, D. (2002), "Following experts at work in their own information spaces: Using observational methods to develop tools for the digital library", Journal of the American Society for Information Science and Technology, Vol. 53 No. 14, pp. 1245-1250.

Hansen, P. and Järvelin, K. (2005), "Collaborative information retrieval in an information-intensive domain", Information Processing \& Management, Vol. 41 No. 5, pp. 1101-1119.

Hansen, P., Shah, C. and Klas, C.-P. (Eds.). (2015), Collaborative Information Seeking, Best Practices, New Domains, New Thoughts, Springer, New York.

Hertzum, M. (2002), "The importance of trust in software engineers' assessment and choice of information sources", Information \& Organization, Vol. 12 No. 1, pp. 1-18.

Hertzum, M. (2008), "Collaborative information seeking: The combined activity of information seeking and collaborative grounding", Information Processing \& Management, Vol. 44 No. 2, pp. 957-962.

Hertzum, M. (2010), "Breakdowns in collaborative information seeking: A study of the medication process", Information Processing \& Management, Vol. 46 No. 6, pp. 646-655.

Hertzum, M., Pejtersen, A.M., Cleal, B. and Albrechtsen, H. (2002), "An analysis of collaboration in three film archives: A case for collaboratories", in Bruce, H., Fidel, R., Ingwersen, P. and Vakkari, P. (Eds.), CoLIS4: Proceedings of the Fourth International Conference on Conceptions of Library and Information Science, Libraries Unlimited, Greenwood Village, CO, pp. 69-83.

Hertzum, M. and Reddy, M. (2015), "Procedures and collaborative information seeking: A study of emergency departments", in Hansen, P., Shah, C. and Klas, C.-P. (Eds.), Collaborative Information Seeking: Best Practices, New Domains and New Thoughts, Springer, Berlin, pp. 55-71.

Hyldegård, J. (2006), "Collaborative information behaviour - Exploring Kuhlthau's information search process model in a group-based educational setting", Information Processing \& Management, Vol. 42 No. 1, pp. 276-298.

Hyldegård, J. (2009a), "Beyond the search process - Exploring group members' information behavior in context", Information Processing \& Management, Vol. 45 No. 1, pp. 142-158.

Hyldegård, J. (2009b), "Personality traits and group-based information behaviour: An exploratory study", Information Research, Vol. 14 No. 2, article 402.

Hyldegård, J., Hertzum, M. and Hansen, P. (2015), "Studying collaborative information seeking: Experiences with three methods", in Hansen, P., Shah, C. and Klas, C.-P. (Eds.), Collaborative Information Seeking: Best Pracices, New Domains and New Thoughts, Springer, Berlin, pp. 17-35.

Isenberg, P. and Fisher, D. (2009), "Collaborative brushing and linking for co-located visual analytics of document collections", Computer Graphics Forum, Vol. 28 No. 3, pp. 1031-1038.

Jetter, H.-C., Gerken, J., Zöllner, M., Reiterer, H. and Milic-Frayling, N. (2011), "Materializing the query with facet-streams - A hybrid surface for collaborative search on tabletops", in Proceedings of the CHI2011 Conference on Human Factors in Computing Systems, ACM Press, New york, pp. 3013-3022.

Joho, H., Hannah, D. and Jose, J.M. (2008), "Comparing collaborative and independent search in a recalloriented task", in Ilix2008: Proceedings of the Second International Symposium on Information Interaction in Context, ACM Press, New York, pp. 89-96. 
Julien, H. and Michels, D. (2004), "Intra-individual information behaviour in daily life", Information Processing \& Management, Vol. 40 No. 3, pp. 547-562.

Kelly, R. and Payne, S.J. (2014), "Collaborative web search in context: A study of tool use in everyday tasks", in Proceedings of the CSCW2014 Conference on Computer Supported Cooperative Work \& Social Computing, ACM Press, New York, pp. 807-819.

Knight, S. and Mercer, N. (2015), "The role of exploratory talk in classroom search engine tasks", Technology, Pedagogy and Education, Vol. 24 No. 3, pp. 303-319.

Knight, S. and Mercer, N. (2017), "Collaborative epistemic discourse in classroom information-seeking tasks", Technology, Pedagogy and Education, Vol. 26 No. 1, pp. 33-50.

Kuhlthau, C.C. (2004), Seeking meaning: a process approach to library and information services (2nd ed.), Libraries Unlimited, Westport, CT.

Kuiper, E., Volman, M. and Terwel, J. (2009), "Developing web literacy in collaborative inquiry activities", Computers \& Education, Vol. 52 No. 3, pp. 668-680.

Landis, J.R. and Koch, G.G. (1977), "The measurement of observer agreement for categorical data", Biometrics, Vol. 33 No. 1, pp. 159-174.

Large, A., Beheshti, J. and Rahman, T. (2002), "Gender differences in collaborative web searching behavior: An elementary school study", Information Processing \& Management, Vol. 38 No. 3, pp. 427-443.

Lazonder, A.W. (2005), "Do two heads search better than one? Effects of student collaboration on web search behaviour and search outcomes", British Journal of Educational Technology, Vol. 36 No. 3, pp. 465-475.

Maekawa, T., Hara, T. and Nishio, S. (2006), "A collaborative web browsing system for multiple mobile users", in Proceedings of the PerCom2006 Conference on Pervasive Computing and communications, IEEE, Washington, DC, pp. 22-35.

McGrath, J.E. (1981), "Dilemmatics: The study of research choices and dilemmas", American Behavioral Scientist, Vol. 25 No. 2, pp. 179-210.

Mitrelis, A., Tsakonas, G. and Papatheodorou, C. (2008), "Using qualitative research methods for the improvement of collaborative information searching tools design", paper presented at the LIDA2008: Libraries in the Digital Age, Dubrovnik and Mljet, Croatia.

Morris, M.R. (2008), "A survey of collaborative web search practices", in Proceedings of the CHI2008 Conference on Human Factors in Computing Systems, ACM Press, New York, pp. 1657-1660.

Morris, M.R. (2013), "Collaborative search revisited", in Proceedings of the CSCW2013 Conference on Computer Supported Cooperative Work, ACM Press, New York, pp. 1181-1192.

Morris, M.R. and Horvitz, E. (2007), "SearchTogether: An interface for collaborative web search", in Proceedings of the UIST2007 Symposium on User Interface Software and Technology, ACM Press, New York, pp. 3-12.

Morris, M.R., Lombardo, J. and Wigdor, D. (2010), "WeSearch: Supporting collaborative search and sensemaking on a tabletop display", in Proceedings of the CSCW2010 Conference on Computer Supported Cooperative Work, ACM Press, New York, pp. 401-410.

Morris, M.R., Paepcke, A. and Winograd, T. (2006), "TeamSearch: Comparing techniques for co-present collaborative search of digital media", in Proceedings of the TABLETOP2006 Workshop on Horizontal Interactive Human-Computer Systems, IEEE, Washington, DC, pp. 97-104.

Morris, M.R. and Teevan, J. (2010), Collaborative web search: Who, what, where, when, and why, Morgan \& Claypool, San Rafael, CA.

Morris, M.R., Teevan, J. and Bush, S. (2008), "Enhancing collaborative web search with personalization: Groupization, smart splitting, and group hit-highlighting", in Proceedings of the CSCW2008 Conference on Computer Supported Cooperative Work, ACM Press, New York, pp. 481-484. 
O'Day, V.L. and Jeffries, R. (1993), "Information artisans: Patterns of result sharing by information searchers", in Proceedings of the COCS1993 Conference on Organizational Computing Systems, ACM Press, New York, pp. 98-107.

Paul, S.A. and Morris, M.R. (2009), "CoSense: Enhancing sensemaking for collaborative web search", in Proceedings of the CHI2009 Conference on Human Factors in Computing Systems, ACM Press, New York, pp. 1771-1780.

Paul, S.A. and Morris, M.R. (2011), "Sensemaking in collaborative web search", Human-Computer Interaction, Vol. 26 No. 1-2, pp. 72-122.

Paul, S.A. and Reddy, M.C. (2010), "Understanding together: Sensemaking in collaborative information seeking", in Proceedings of the CSCW2010 Conference on Computer Supported Cooperative Work, ACM Press, New York, pp. 321-330.

Poltrock, S., Grudin, J., Dumais, S., Fidel, R., Bruce, H. and Pejtersen, A.M. (2003), "Information seeking and sharing in design teams", in Proceedings of the GROUP2003 Conference on Supporting Group Work, ACM Press, New York, pp. 239-247.

Prekop, P. (2002), "A qualitative study of collaborative information seeking", Journal of Documentation, Vol. 58 No. 5, pp. 533-547.

Reddy, M. and Jansen, B.J. (2008), "A model for understanding collaborative information behavior in context: A study of two healthcare teams", Information Processing \& Management, Vol. 44 No. 1, pp. 256-273.

Reddy, M.C., Jansen, B.J. and Krishnappa, R. (2008), "The role of communication in collaborative information searching", Proceedings of the American Society for Information Science and Technology, Vol. 45 No. 1, pp. 1-10.

Reddy, M.C. and Spence, P.R. (2008), "Collaborative information seeking: A field study of a multidisciplinary patient care team", Information Processing \& Management, Vol. 44 No. 1, pp. 242255.

Shah, C. (2010), "Collaborative information seeking: A literature review", in Woodsworth, A. (Ed.), Advances in Librarianship (Vol. 32), Emerald, Bingley, UK, pp. 3-33.

Shah, C. (2012), Collaborative information seeking: The art and science of making the whole greater than the sum of all, Springer, New York.

Shah, C. (2014), "Collaborative information seeking", Journal of the Association for Information Science and Technology, Vol. 65 No. 2, pp. 215-236.

Shah, C., Capra, R. and Hansen, P. (2014), "Collaborative information seeking", IEEE Computer, Vol. 47 No. 3, pp. 22-25.

Shah, S. (2013), "Effects of awareness on coordination in collaborative information seeking", Journal of the American Society for Information Science and Technology, Vol. 64 No. 6, pp. 1122-1143.

Shah, S. and González-Ibáñez, R. (2012), "Spatial context in collaborative information seeking", Journal of Information Science, Vol. 38 No. 4, pp. 333-349.

Shapira, B., Kantor, P.B. and Melamed, B. (2001), "The effects of extrinsic motivation on user behavior in a collaborative information finding system", Journal of the American Society for Information Science and Technology, Vol. 52 No. 11, pp. 879-887.

Smeaton, A.F., Lee, H., Foley, C. and McGivney, S. (2007), "Collaborative video searching on a tabletop", Multimedia Systems, Vol. 12 No. 4, pp. 375-391.

Soulier, L., Shah, S. and Tamine, L. (2014), "User-driven system-mediated collaborative information retrieval", in Proceedings of the SIGIR2014 Conference on Research and Development in Information Retrieval, ACM Press, New York, pp. 485-494.

Spence, P.R. and Reddy, M.C. (2007), "The "active" gatekeeper in collaborative information seeking activities", in Proceedings of the GROUP2007 Conference on Supporting Group Work, ACM Press, New York, pp. 277-280. 
Spence, P.R., Reddy, M.C. and Hall, R. (2005), "A survey of collaborative information seeking practices of academic researchers", in Proceedings of the GROUP2005 Conference on Supporting Group Work, ACM Press, New York, pp. 85-88.

Tamine, L. and Soulier, L. (2015), "Understanding the impact of the role factor in collaborative information retrieval", in Proceedings of the CIKM2015 Conference on Information and Knowledge Management, ACM Press, New York, pp. 43-52.

Tamine, L. and Soulier, L. (2016), "Collaborative information retrieval: Concepts, models and evaluation", in Ferro, N., Crestani, F., Moens, M.-F., Mothe, J., Silvestri, F., Nunzo, G.M.D., Hauff, C. and Silvello, G. (Eds.), ECIR2016: Proceedings of the European Conference on Information Retrieval, Springer, New York, pp. 885-888.

Tao, Y. and Tombros, A. (2013), "An exploratory study of sensemaking in collaborative information seeking", in ECIR2013: Proceedings of the European Conference on Information Retrieval, Springer, Berlin, pp. 26-37.

Twidale, M.B. and Nichols, D.M. (1996), "Collaborative browsing and visualization of the search process", ASLIB Proceedings, Vol. 48 No. 7-8, pp. 177-182.

Twidale, M.B., Nichols, D.M., Smith, G. and Trevor, J. (1995), "Supporting collaborative learning during information searching", in Proceedings of the CSCL1995 Conference on Computer Support for Collaborative Learning, Erlbaum, Hillsdale, NJ, pp. 367-374.

Wilson, T.D. (1999), "Models in information behaviour research", Journal of Documentation, Vol. 55 No. 3, pp. 249-270.

Yue, Z., Han, S. and He, D. (2012), "An investigation of search processes in collaborative exploratory web search", Proceedings of the American Society for Information Science and Technology, Vol. 49 No. 1, pp. 1-4.

Zhou, N. and Stahl, G. (2007), "Towards building a math discourse community: Investigating collaborative information behavior", in OCSC2007: Proceedings of the International Conference on Online Communities and Social Computing, Springer, Berlin, pp. 509-518. 